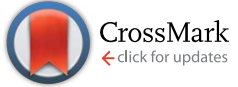

Cite this: RSC Adv., 2014, 4, 42029

\title{
Natural product mixture analysis by matrix-assisted DOSY using Brij surfactants in mixed solvents $\uparrow$
}

\author{
Mariano G. S. Vieira, ${ }^{a}$ Nilce V. Gramosa, ${ }^{a}$ Nágila M. P. S. Ricardo, ${ }^{a}$ Gareth A. Morris, ${ }^{b}$ \\ Ralph W. Adams ${ }^{\mathrm{b}}$ and Mathias Nilsson ${ }^{\star b c}$
}

The assignment of NMR signals to specific components in a mixture is a challenging task. Diffusion-Ordered Spectroscopy (DOSY) has provided important progress in this area, allowing the signals originating from individual components of different molecular sizes to be distinguished. However, when the sizes of the compounds are similar and/or the spectra are overlapped, signal assignment can easily become intractable. The use of a co-solute in a matrix-assisted DOSY (MAD) experiment can be a useful solution, improving diffusional (and sometimes spectral) resolution by exploiting selective binding to the matrix. MAD has generated promising results in the study of several types of mixtures, including those of functional and structural isomers. The challenge is to apply MAD to molecules with high structural similarity, for example in natural product mixtures. Various surfactants, including SDS, AOT and CTAB have previously been shown to be effective in MAD analysis. Here we present an important addition, the Brij family of nonionic surfactants. We demonstrate the use of Brij micelles in mixed solvents with a variety of mixtures relevant to natural products.

Received 12th May 2014

Accepted 18th August 2014

DOI: $10.1039 / c 4 r a 04433 a$

www.rsc.org/advances separation of signals in a "matrix-assisted DOSY" (MAD) experiment. ${ }^{6}$

In a successful MAD experiment, the analytes interact to different extents with a slowly-diffusing co-solute (e.g. micellar surfactant) in fast exchange. The average solute diffusion coefficient, $D_{\mathrm{av}}$, is then given by Lindman's law:

$$
D_{\mathrm{av}}=D_{\mathrm{u}} p_{\mathrm{u}}+D_{\mathrm{b}} p_{\mathrm{b}}
$$

where $D_{\mathrm{u}}$ and $p_{\mathrm{u}}$ and $D_{\mathrm{b}}$ and $p_{\mathrm{b}}$ are the diffusion coefficients and the fractions of unbound and bound solute molecules respectively. $^{7}$

MAD has been used in the resolution of a variety of organic mixtures, including mixtures of isomers, exploiting selective cosolute binding that depends on such factors as polarity, amphiphilicity and stereochemistry, resulting in altered diffusion coefficients and allowing the separation of the individual component spectra. SDS and AOT (micelles and reverse micellar aggregates, respectively) have been shown to be useful tools in the separation of signals of dihydroxybenzenes, ${ }^{6}$ monomethoxyphenols $^{8,9}$ (in both cases positional isomers), and medium chained alcohols ${ }^{9}$ in MAD experiments. SDS micelles have also been used with a mixed solvent system, allowing complete identification of each component in flavonoid mixtures. ${ }^{10}$ Polymers like polyvinylpyrrolidone (PVP) ${ }^{\mathbf{1 1}}$ and polyethylene glycol (PEG) ${ }^{12}$ have also been used as efficient matrices in MAD. $\beta$-Cyclodextrin ${ }^{13,14}$ has been used as a chiral matrix, allowing the resolution of a mixture of two native epimers of naringin. ${ }^{13}$ Microemulsions have been used to
${ }^{a}$ Department of Organic and Inorganic Chemistry, Federal University of Ceara Fortaleza, Ceara, CP 12 200, Brazil

${ }^{b}$ School of Chemistry, University of Manchester, Oxford Road, Manchester, M13 9PL, UK. E-mail: mathias.nilsson@manchester.ac.uk

${ }^{c}$ Department of Food Science, University of Copenhagen, Rolighedsvej 30, DK-1958 Frederiksberg C, Denmark

$\dagger$ Electronic supplementary information (ESI) available. See DOI: 10.1039/c4ra04433a 
separate the component signals in commercial drug formulations. ${ }^{15}$ A simple change of solvent can also be effective. ${ }^{16}$

Even solids like silica $\left(\mathrm{SiO}_{2}\right)$ powder and ODS - (octadecylsilane) coated chromatographic stationary phases can be used as matrices, and have been shown to allow the separation of signals in a mixed, homologous series of aromatic compounds. ${ }^{17}$ When a solid matrix is used, an HRMAS-DOSY ${ }^{18}$ experiment may be needed to provide adequate signal resolution. Satisfactory resolution of signals has been demonstrated in such experiments, but one complication is of course the necessity for sufficient resolution in the chemical shift dimension, which is more difficult to achieve in heterogeneous media. ${ }^{19}$ Here, choosing a liquid phase that is matched in magnetic susceptibility to the solid can allow standard liquidstate NMR methods to be applied. ${ }^{20}$ Silica-based methods predominantly separate solute signals according to their hydrogen-bonding affinity, primarily distinguishing between solutes with different functional groups. ${ }^{21}$

Flavonoids are an important family of natural compounds with interesting biological properties, most importantly as antioxidants; ${ }^{22}$ over 4000 types of flavonoid compounds have been identified in vascular plants. ${ }^{23}$ Monoterpenes are also important compounds, and are the main constituents in the majority of plant essential oils. They give plants their unique odoriferous properties and are volatile because of their low boiling points. ${ }^{24}$ HPLC is often used to separate the components of plant extracts, with the fractions then being identified and characterised using mass spectrometry and/or NMR. ${ }^{25}$ The use of DOSY (and MAD) can enable identification directly in an intact mixture, or in a fraction containing inseparable components. Most MAD analyses have hitherto been performed in aqueous solution, in which many natural product compounds of interest, including monoterpenes, have low solubility. It is therefore of interest to explore alternative solvent systems in which the solubilities of these compounds are higher.

Various surfactants, including SDS, AOT and CTAB, have already been used in MAD analysis, ${ }^{\mathbf{6 , 8}, 9}$ but not the Brij family of

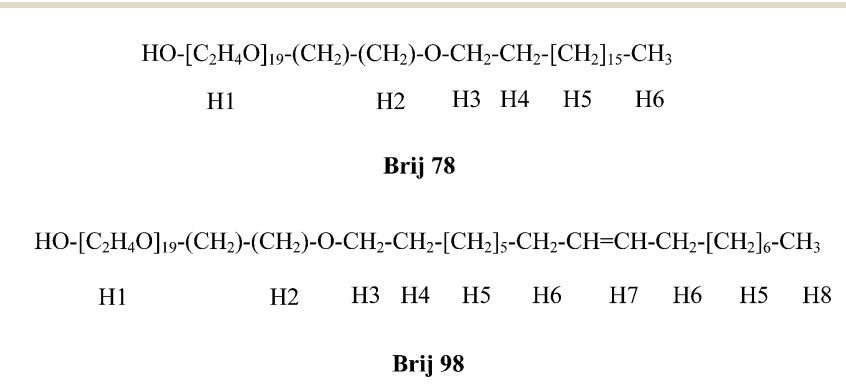

Scheme 1 Structures of Brij 78 and Brij 98. nonionic surfactants. These consist of a hydrophilic head containing a variable number of polyoxyethylene groups, and a hydrophobic polymethylene tail. ${ }^{26}$ Brij surfactants have been used as carriers in drug delivery ${ }^{27}$ due to their low toxicity, ${ }^{28}$ and in solubilization of drugs that have low water solubility. ${ }^{26}$ Previous studies have shown that surfactants like SDS can form micelles in binary solvent systems, ${ }^{29,30}$ but there are no such reports for the Brij family. Here, we demonstrate the use of Brij 78 and 98 (Scheme 1; Table 1) in mixed water-DMSO solution in MAD experiments primarily aimed at molecules with low solubility in water.

\section{Results and discussion}

Micelle formation of Brij 78 and 98 was investigated in the mixed solvents used. Critical micelle concentrations (CMC) were determined using DOSY experiments on surfactant solutions ranging in concentration from 1.0 to $15.0 \mathrm{mM}$. For Brij 78, these solutions were in $20 \%$ DMSO- $\mathrm{d}_{6}-80 \% \mathrm{D}_{2} \mathrm{O}(\mathrm{v} / \mathrm{v})$ and for


Fig. 1 Plot of measured diffusion coefficient, $D$, against inverse of total surfactant concentration (a) for Brij 78 in 20\% DMSO- $d_{6}-80 \% D_{2} \mathrm{O}$ $(\mathrm{v} / \mathrm{v})(\mathrm{b})$ for Brij 98 in 50\% DMSO- $\mathrm{d}_{6}-50 \% \mathrm{D}_{2} \mathrm{O}(\mathrm{v} / \mathrm{v})$.

Table 1 Selected properties of the Brij surfactants

\begin{tabular}{llll}
\hline Trade name & Average molecular formula & Molar mass $\left(\mathrm{g} \mathrm{mol}^{-1}\right)$ & $\mathrm{CMC}^{a}\left(\mathrm{mM}^{2}\right)$ \\
\hline Brij 78 & $\mathrm{C}_{18} \mathrm{H}_{37}\left(\mathrm{OCH}_{2} \mathrm{CH}_{2}\right)_{20} \mathrm{OH}$ & 1152 & 0.046 (ref. 31) \\
Brij 98 & $\mathrm{C}_{18} \mathrm{H}_{35}\left(\mathrm{OCH}_{2} \mathrm{CH}_{2}\right)_{20} \mathrm{OH}$ & 1150 & 0.025 (ref. 32)
\end{tabular}

${ }^{a}$ Reported critical micelle concentration in water at $25{ }^{\circ} \mathrm{C} .{ }^{b}$ Critical micelle concentration measured in DMSO- $\mathrm{d}_{6}-\mathrm{D}_{2} \mathrm{O}$. 
<smiles>Cc1ccc(C(C)C)cc1O</smiles><smiles>Cc1ccc(C(C)C)c(O)c1</smiles><smiles>C=C(C)C1CC=CC(=O)C1</smiles><smiles>O=c1c(O)c(-c2ccc(O)c(O)c2)oc2cc(O)cc(O)c12</smiles><smiles>CCCCO</smiles>

$\mathrm{HO}$<smiles>Cc1cc(O)c2c(c1)OC(c1ccc(O)c(O)c1)C(O)C2</smiles>

Scheme 2 Structures of the monoterpenes carvacrol (1), thymol (2) and L-(-)-carvone (3) and flavonoids quercetin (4), fisetin (5) and $(+)$-catechin (6).

Brij 98 in 50\% DMSO-d ${ }_{6}-50 \% \mathrm{D}_{2} \mathrm{O}(\mathrm{v} / \mathrm{v})$. CMC's were determined by plotting the diffusion coefficient $D$ against the inverse of Brij concentration. Straight lines were fitted above and below the break point, one corresponding to the monomeric and other to the partially aggregated forms of Brij. The CMC value was taken as the intersection of these two lines (Fig. 1).

The Brij $78 \mathrm{CMC}$ changed from a reported value of $0.046 \mathrm{mM}$ in pure $\mathrm{D}_{2} \mathrm{O}$ (ref. 31 ) to $8.0 \mathrm{mM}$ in $20 \%$ DMSO- $_{6}-80 \% \mathrm{D}_{2} \mathrm{O}(\mathrm{v} / \mathrm{v})$, and that of Brij 98 from a reported value in pure $\mathrm{D}_{2} \mathrm{O}$ of 0.025 $\mathrm{mM}$ (ref. 32) to $6.7 \mathrm{mM}$ in $50 \%$ DMSO- $\mathrm{d}_{6}-50 \% \mathrm{D}_{2} \mathrm{O}(\mathrm{v} / \mathrm{v})$.
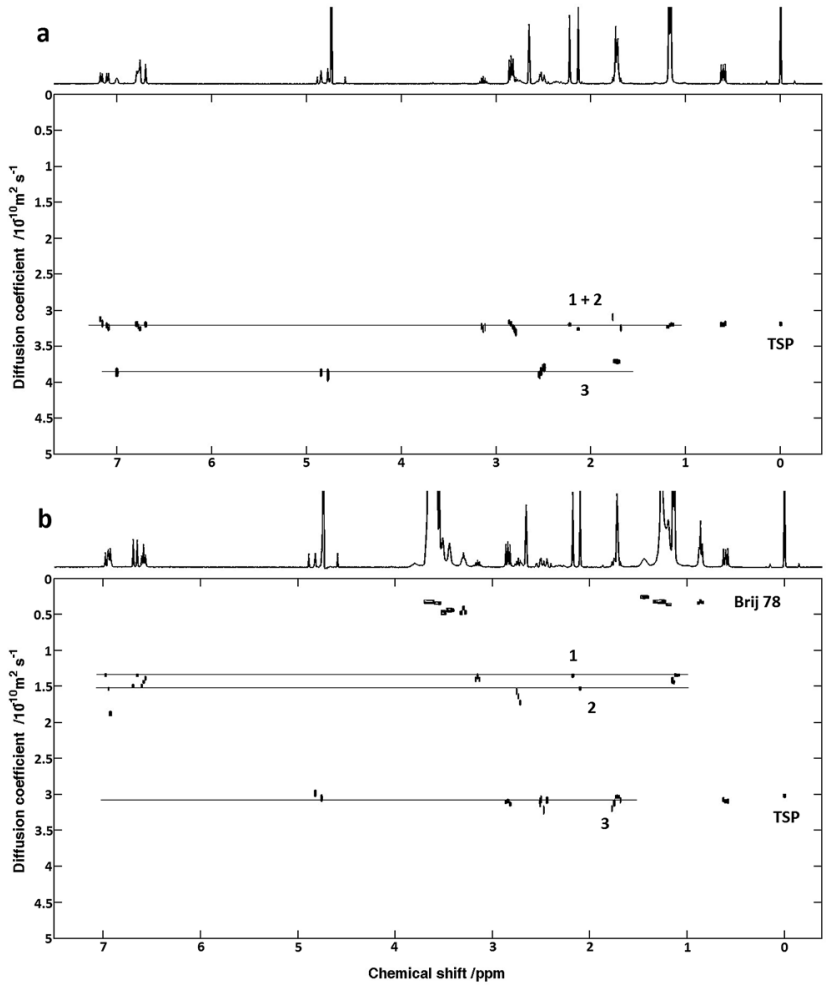

Fig. 2 Oneshot DOSY spectra of monoterpenes 1, 2 and 3, in 20\% DMSO $-d_{6}-80 \% D_{2} \mathrm{O}(\mathrm{v} / \mathrm{v})$ before (a) and after (b) addition of $5 \mathrm{mM}$ Brij 78 .

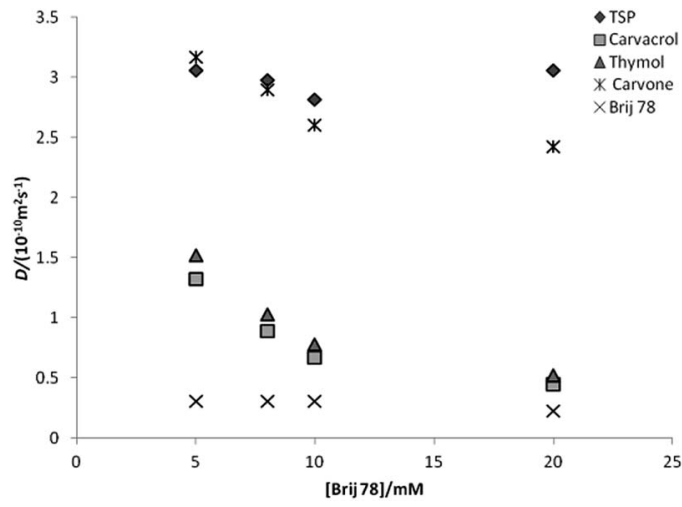

Fig. 3 Diffusion coefficients as a function of Brij 78 concentration for a $20 \% \quad$ DMSO $-d_{6}-80 \% \quad D_{2} \mathrm{O}(\mathrm{v} / \mathrm{v})$ solution containing trimethylsilyl propionate (TSP) as reference and $3.0 \mathrm{mM}$ of each of monoterpenes 1 , 2 and 3.

The CMC behavior of various PEO-block copolymers has been investigated in water-ethanol mixed solvents. ${ }^{33-35}$ These studies have shown that the CMC increased after addition of ethanol. The addition of DMSO- $\mathrm{d}_{6}$ to $\mathrm{D}_{2} \mathrm{O}$ seems to show the same tendency, providing better solvent conditions for the Brij 78 and 98 compared to pure $\mathrm{D}_{2} \mathrm{O}$ and disfavoring the formation of micelles (self-assembly). Further thermodynamic studies would be useful to understand this observation better.

To demonstrate the use of DOSY and MAD for mixtures containing monoterpenes and flavonoids, a test system of 6
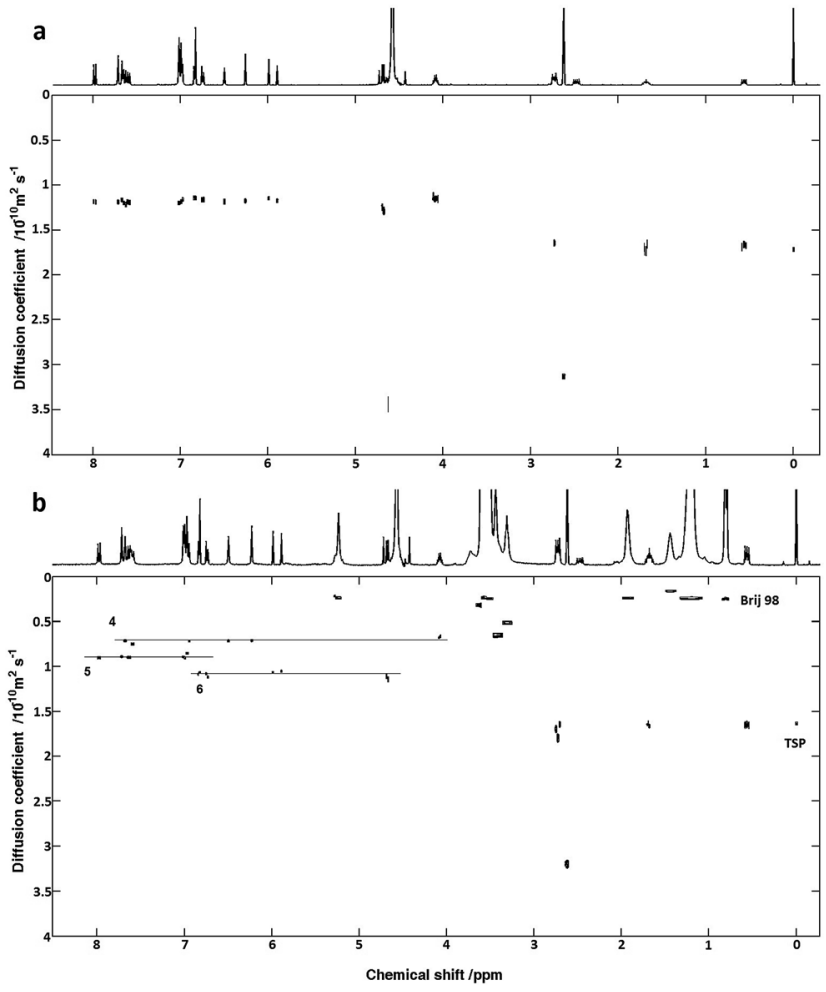

Fig. 4 Oneshot DOSY spectra of flavonoids 4, 5 and 6, before (a) and after (b) addition of Brij $98(10 \mathrm{mM})$ in 50\% v/v DMSO- $\mathrm{d}_{6}-\mathrm{D}_{2} \mathrm{O}$. Contour levels are set to show a representative proportion of reporter signals. 
compounds (Scheme 2) was chosen for analysis. Standard DOSY spectra of a mixture of the monoterpenes (Scheme 2, compounds 1-3) in 20\% DMSO- $\mathrm{d}_{6}-80 \% \mathrm{D}_{2} \mathrm{O}(\mathrm{v} / \mathrm{v})$ shows a separation of $\mathrm{L}_{-}(-)$-carvone (3) signals from those of the other two compounds, carvacrol (1) and thymol (2) (Fig. 2a). This is unexpected given the very similar molecular weights, but may reflect both the difference in shape and the reduced propensity to hydrogen bonding, and shows the potential of DOSY to separate the signals even of quite similar species.

Adding Brij 78, the monoterpenes 1 and 2 show strong association with the micelles, while compound 3 interacts only weakly. The strength of interaction with Brij 78 is clearly different for compounds $\mathbf{1}$ and 2, and the signals separate in the diffusion domain (Fig. 2b), making it possible to identify all of the three compounds. On addition of Brij 98, resolution of $\mathbf{1}$ and 2 is less pronounced and when using SDS in $20 \%$ DMSO- $_{6}-$ $80 \% \mathrm{D}_{2} \mathrm{O}(\mathrm{v} / \mathrm{v})$ as co-solute, no resolution is observed between 1 and 2 (results not shown). The effect of Brij 78 concentration was investigated using samples containing $3.0 \mathrm{mM}$ of each monoterpene (Fig. 3) with best resolution achieved at $5.0 \mathrm{mM}$ surfactant.

For the flavonoid mixture (Scheme 2, compounds 4, 5 and 6), the standard DOSY spectrum in $50 \%$ DMSO- $\mathrm{d}_{6}-50 \% \mathrm{D}_{2} \mathrm{O}(\mathrm{v} / \mathrm{v})$ shows all signals having very similar diffusion coefficients (Fig. 4a). On adding Brij 98, the signals of the three flavonoids become well resolved in the diffusion dimension, allowing

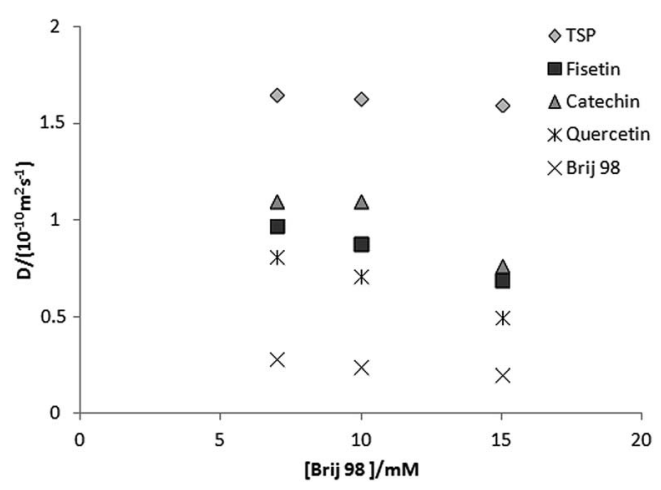

Fig. 5 Diffusion coefficients as a function of Brij 98 concentration for a $50 \% \mathrm{v} / \mathrm{v}$ DMSO $-\mathrm{d}_{6}-\mathrm{D}_{2} \mathrm{O}$ solution containing with trimethylsilyl propionate (TSP) as reference and $5.0 \mathrm{mM}$ of each flavonoid. individual characterization (Fig. 4b) and improving on earlier results obtained with SDS. ${ }^{10}$ The effect of Brij 98 concentration was also investigated using samples containing $5.0 \mathrm{mM}$ of each of the flavonoids (Fig. 5). The best resolution was obtained with $10 \mathrm{mM}$ of Brij 98; the CMC in this mixed solvent was measured as $8.0 \mathrm{mM}$ (Fig. 1).

Brij 78 proved to be insoluble in $50 \%$ DMSO- $\mathrm{d}_{6}-50 \% \mathrm{D}_{2} \mathrm{O}(\mathrm{v} /$ $\mathrm{v})$, not allowing analysis of the flavonoid mixtures.

Comparing the chemical shifts of the Brij signals before and after addition of interacting compounds can give some insight into the nature of the association between solute and micelle. Changes for particular resonances suggest that the local environment surrounding the corresponding hydrogen atom has changed, evidencing the presence of the solute near that hydrogen. ${ }^{36,37}$

For Brij 78, the peaks corresponding to the protons on the first ethoxylate group and others close by (3.54, 3.41 and 1.54 ppm, respectively) experienced the greatest upfield shift in the presence of $\mathrm{L}_{-}-(-)$-carvone (1), thymol (2) and carvacrol (3). The remaining ethylene oxide chain showed little change in chemical shift and the nonpolar chain showed no change (Table 2).

For the monoterpenes, the strength of binding increases in the order carvone $<$ thymol $<$ carvacrol, the same order as that of estimated octanol-water partition coefficient $(\log P): 2.70,3.34$ and 3.82, respectively (estimated using Molinspiration Cheminformatics ${ }^{\circledR}$ software tool $)^{38}$ as a measure of molecular hydrophobicity. This is consistent with the hypothesis of incorporation into a micellar core. However, considering the hydrocarbon chain as the core of the micelle and the ethoxylate chain as the shell region, in the Brij 78 case it would appear that the monoterpenes are preferentially bound at the core/shell interface.

Brij 98 exhibits a different pattern to Brij 78, with all protons in the chain exhibiting changes in chemical shift in the presence of quercetin (4), fisetin (5) and (+)-catechin (6). The hydrocarbon chain closest to the EO chain (H3 and H4) experiences the greatest upfield shift upon addition of flavonoids. The EO chain (H1) and the nonpolar chain (H8) also experience chemical shift changes, but to a smaller degree (Table 2). As with the monoterpenes, the flavonoids appear to be concentrated at the core/shell interface, but their effects spread throughout the EO and hydrocarbon chains, presumably because of their significantly larger size.

Table 2 Proton NMR chemical shifts for Brij $78(5 \mathrm{mM})$ and Brij $98(10 \mathrm{mM})$ and changes in shift with solutes

\begin{tabular}{lllll}
\hline & Chemical shift in Brij 78 & Upfield shift ${ }^{a}(\Delta \mathrm{ppm})$ & Chemical shift in Brij $98^{\text {Upfield shift }^{b}(\Delta \text { ppm })^{2}}$ \\
\hline H1 & 3.66 & 0.01 & 3.59 & 0.01 \\
H2 & 3.54 & 0.10 & 3.46 & 0.02 \\
H3 & 3.41 & 0.11 & 3.34 & 0.03 \\
H4 & 1.54 & 0.10 & 1.47 & 0.03 \\
H5 & 1.26 & 0.00 & 1.21 & 0.01 \\
H6 & 0.86 & 0.00 & 1.95 & 0.02 \\
H7 & - & - & 5.25 & 0.02 \\
H6 & - & - & 0.82 & 0.02
\end{tabular}

${ }^{a}$ With addition of $3.0 \mathrm{mM}$ of monoterpenes 1,2 and $3 .{ }^{b}$ With addition of $5.0 \mathrm{mM}$ of flavonoids 4,5 and 6. 


\section{Conclusions}

We demonstrate efficient methodologies for NMR analysis of monoterpene and flavonoid mixtures, using for the first time nonionic Brij surfactants in binary solvent mixtures in MAD experiments. In the particular cases studied, Brij 78 and 98 showed better discrimination than SDS, the surfactant currently most commonly used in MAD.

\section{Experimental section}

NMR experiments were carried out non-spinning on a Varian Inova $400 \mathrm{MHz}$ spectrometer. Temperature control was set to 25 ${ }^{\circ} \mathrm{C}$. The Oneshot pulse sequence ${ }^{4,39}$ was used for DOSY experiments, using a diffusion-encoding pulse width $(\delta)$ of $3 \mathrm{~ms}$, a diffusion delay $(\Delta)$ of $200 \mathrm{~ms}$ and nominal gradient strengths ranging from 5.0 to $27.0 \mathrm{G} \mathrm{cm}^{-1}$ with 32 gradient amplitudes increased in equal steps of gradient squared. TSP was used as internal reference for reference deconvolution ${ }^{40}$ in all the samples. All processing was done in the DOSY Toolbox, ${ }^{\mathbf{4 1}}$ and in all DOSY processing the data were corrected for the effect of non-uniform pulsed field gradients. ${ }^{42}$

Experiments carried out to determine the Brij critical micelle concentrations (CMCs) were performed with a diffusionencoding pulse width $(\delta)$ of $4.5 \mathrm{~ms}$ and a diffusion delay $(\Delta)$ of $400 \mathrm{~ms}$, using Brij solutions prepared by dilution from a stock solution.

\section{Acknowledgements}

This work was supported by the Engineering and Physical Sciences Research Council (Grant Numbers EP/H024336/ and, $\mathrm{EP} / \mathrm{I007989/1)}$, and thanks are offered to the CAPES Foundation, Ministry of Education of Brazil, Brasília, Brazil.

\section{Notes and references}

1 C. S. Johnson Jr, Prog. Nucl. Magn. Reson. Spectrosc., 1999, 34, 203.

2 G. A. Morris, in Encyclopedia of Nuclear Magnetic Resonance, ed. D. M. Grant and R. K. Harris, John Wiley \& Sons Ltd, 2002, vol. 9.

3 O. E. Stejskal and J. E. Tanner, J. Chem. Phys., 1965, 42, 288.

4 M. D. Pelta, G. A. Morris, M. J. Stchedroff and S. J. Hammond, Magn. Reson. Chem., 2002, 40, S147-S152.

5 A. Botana, J. A. Aguilar, M. Nilsson and G. A. Morris, J. Magn. Reson., 2011, 208, 270.

6 R. Evans, S. Haiber, M. Nilsson and G. A. Morris, Anal. Chem., 2009, 81, 4548.

7 B. Lindman and B. Brun, J. Colloid Interface Sci., 1973, 42, 388.

8 C. F. Tormena, R. Evans, S. Haiber, M. Nilsson and G. A. Morris, Magn. Reson. Chem., 2010, 48, 550.

9 C. F. Tormena, R. Evans, S. Haiber, M. Nilsson and G. A. Morris, Magn. Reson. Chem., 2012, 50, 458.

10 J. Cassani, M. Nilsson and G. A. Morris, J. Nat. Prod., 2012, 75, 131.
11 J. S. Kavakka, I. Kilpeläinen and S. Heikkinen, Org. Lett., 2009, 11, 1349.

12 J. S. Kavakka, V. Parviainen, K. Wähälä, I. Kilpeläinen and S. Heikkinen, Magn. Reson. Chem., 2010, 48, 777.

13 R. W. Adams, J. A. Aguilar, J. Cassani, G. A. Morris and M. Nilsson, Org. Biomol. Chem., 2011, 9, 7062.

14 S. R. Chaudhari, Srinivasa and N. Suryaprakash, J. Mol. Struct., 2013, 1033, 75.

15 C. Pemberton, R. E. Hoffman, A. Aserin and N. Garti, Langmuir, 2011, 27, 4497.

16 D. J. Codling, G. Zheng, T. Stait-Gardner, S. Yang, M. Nilsson and W. S. Price, J. Phys. Chem. B, 2013, 117, 2734.

17 G. Pages, C. Delaurent and S. Caldarelli, Angew. Chem., Int. Ed., 2006, 45, 5950.

18 S. Viel, F. Ziarelli and S. Caldarelli, Proc. Natl. Acad. Sci. U. S. A., 2003, 100, 9696.

19 P. T. Callaghan, Principles of Nuclear Magnetic Resonance Microscopy, Oxford Science, Oxford, 1st edn, 1991, p. 516.

20 R. E. Hoffman, H. Arzuan, C. Pemberton, A. Aserin and N. Garti, J. Magn. Reson., 2008, 194, 295.

21 C. Pemberton, R. E. Hoffman, A. Aserin and N. Garti, J. Magn. Reson., 2011, 208, 262.

22 P. G. Pietta, J. Nat. Prod., 2000, 63, 1035.

23 W. S. Pierpoint, Flavonoids in the human diet, in Plant Flavonoids in Biology and Medicine: Biochemical, Pharmacological and Structure-Activity Relationships, ed. V. Cody, E. Middleton Jr and J. Harborne, New York, USA, 1986.

$24 \mathrm{~W}$. Templeton, An introduction to the chemistry of the terpenoids and steroids, Butterworths, London, 1969.

25 C. Seger, S. Sturm and H. Stuppner, Nat. Prod. Rep., 2013, 30, 970.

26 M. E. N. P. Ribeiro, C. L. Moura, M. G. S. Vieira, N. V. Gramosa, C. Chaibundit, M. C. Mattos, D. Attwood, S. G. Yeates, S. K. Nixon and N. M. P. S. Ricardo, Int. J. Pharm., 2012, 436, 631.

27 Y. Kapoor, J. C. Thomas, G. Tan, V. T. John and A. Chauhan, Biomaterials, 2009, 30, 867.

28 M. Sowmiya, A. K. Tiwari and S. K. Saha, J. Colloid Interface Sci., 2010, 344, 97.

29 S. A. Markarian, L. R. Harutyunyan and R. S. Harutyunyan, J. Solution Chem., 2005, 34, 361.

30 M. S. Chauhan, G. Kumar, A. Kumar, K. Sharma and S. Chauhan, Colloids Surf., A, 2001, 180, 111.

31 C. Klammt, D. Schwartz, K. Fendler, W. Haase, V. Dotsch and F. Bernhard, FEBS J., 2005, 212, 6024.

32 P. Becher, J. Phys. Chem., 1959, 63, 1675.

33 J. Armstrong, B. Chowdhy, J. Mitchell, A. Beezer and S. Lehame, J. Phys. Chem., 1996, 100, 1738.

34 C. Chaibundit, N. Ricardo, F. Costa, M. G. P. Wong, D. Hermida-Merino, J. Rodriguez Perez, I. W. Hamley, S. G. Yeates and C. Booth, Langmuir, 2008, 24, 12260.

35 B. Sarkar, V. Ravi and P. Alexandridis, J. Colloid Interface Sci., 2013, 390, 137.

36 L. A. Bernardez, Colloids Surf., A, 2008, 324, 71.

37 D. J. L. Prak, W. I. Jahraus, J. M. Sims and A. H. R. MacArthur, Colloids Surf., A, 2011, 375, 12. 
38 Molinspiration Cheminformatics, Bratislava, Slovak Republic, available: http://www.molinspiration.com/services/properties. html.

39 A. Botana, J. A. Aguilar, M. Nilsson and G. A. Morris, J. Magn. Reson., 2011, 208, 270.
40 G. A. Morris, H. Barjat and T. J. Horne, Prog. Nucl. Magn. Reson. Spectrosc., 1997, 31, 197.

41 M. Nilsson, J. Magn. Reson., 2009, 200, 296.

42 M. A. Connell, P. J. Bowyer, A. P. Bone, A. L. Davis, A. G. Swanson, M. Nilsson and G. A. Morris, J. Magn. Reson., 2009, 198, 121. 